\title{
Do we need to redefine the advanced stage in Parkinson's disease?
}

\author{
Ángel Sesar*, Gustavo Fernández-Pajarín, Begoña Ares, and Alfonso Castro \\ Neurology Department, Movement Disorder Unit, Hospital Clínico Universitario, Santiago de Compostela, Spain
}

\begin{abstract}
Identifying the advanced stage in Parkinson's disease (PD) is crucial for shifting from conventional to device-aided therapies. The criteria to define the onset of advanced PD have been based on lengthy and disabling daily off-times, troublesome dyskinesia and complex therapeutic regimes, but have also included invalidating non-dopaminergic symptoms, such as dementia, falls or dysphagia. These last problems usually appear in a much later stage of the advanced PD. The key to the definition of advanced PD should be the lack of adequate PD control of both motor and non-motor dopaminergic symptoms. The patient's judgment about the quality of their response to conventional therapy is also critical to establish the advanced stage. The early identification of this phase allows maintaining the patient's functional state whenever appropriate treatments are applied. We should keep the term advanced stage when the dopaminergic symptoms responsive to device-aided therapy are preponderant. When invalidating non-dopaminergic symptoms dominate the clinical picture, the term post-advanced stage could be more suitable.
\end{abstract}

Key words: Parkinson's disease. Advanced stage. Post-advanced stage. Dopaminergic symptoms. Non-dopaminergic symptoms.

\section{¿Necesitamos redefinir el estado avanzado en la enfermedad de Parkinson?}

\section{Resumen}

La identificación del estadio avanzado en la enfermedad de Parkinson (EP) es crucial para el cambio del tratamiento convencional al de segunda línea. Los criterios para definir el inicio de la EP avanzada se han basado en períodos off largos e invalidantes, discinesias molestas y regímenes terapéuticos complejos, pero también se han incluido síntomas no dopaminérgicos graves, como demencia, caídas o disfagia. Estos últimos problemas habitualmente ocurren en un estado de la EP avanzada más tardío. La clave para la definición de EP avanzada está en la falta de control adecuado tanto de síntomas motores como no motores. La opinión del paciente sobre la respuesta o su falta al tratamiento convencional debería ser clave para la definición del estadio avanzado. Su identificación temprana permite mantener la calidad de vida del paciente, siempre que se aplique el tratamiento apropiado. Deberíamos utilizar el término enfermedad avanzada para la fase en que dominan los síntomas dopaminérgicos que responden a los tratamientos de segunda línea. Cuando los síntomas no dopaminérgicos invalidantes dominan el cuadro clínico, el término estadio sobrepasado parece más adecuado.

Palabras clave: Enfermedad de Parkinson. Estadio avanzado. Estadio sobrepasado. Síntomas dopaminérgicos. Síntomas no dopaminérgicos.

\section{Correspondence:}

*Ángel Sesar

E-mail: angel.sesar.ignacio@sergas.es
Available online: 07-07-2021

Rev Mex Neuroci. 2021;22(4):152-158 www.revmexneurociencia.com 2604-6180/ @ 2020 Academia Mexicana de Neurología A.C. Published by Permanyer. This is an open access article under the CC BY-NC-ND license (http://creativecommons.org/licenses/by-nc-nd/4.0/). 


\section{Introduction}

Parkinson's disease (PD) is a chronic process that may affect the patient for many years and goes through various stages ${ }^{1}$. Most authors divide the disease's natural history into a premotor or prodromal stage, an early stage, an intermediate stage, and an advanced stage. During the early stage, dopaminergic drugs at low doses provide good control for the whole day. In the intermediate stage, frequent drug adjustments are needed to control the symptoms. The advanced stage occurs when conventional therapy (see below) does not provide the patient with an adequate disease control ${ }^{2}$.

Although the term advanced PD has been widely used, it is still not very well-defined ${ }^{3}$. Identifying it clearly is a key issue since we have specific treatments for this stage.

In this review, we try to analyze the advanced PD fundamentals. First of all, we divide the parkinsonian symptoms according to their response to dopaminergic medication, the only available. Both conventional and device-aided treatments only act on dopaminergic symptoms. The failure of the first group marks the onset of advanced PD. This should lead to a switch to device-aided therapies. Unfortunately, this is not always the case. Not infrequently, patients are referred to surgery or infusion therapies after years with poor control on conventional therapy. We describe the works of different groups searching for criteria to identify patients with advanced PD and their limitations, in our opinion. Finally, we propose some keys to improve the identification of this stage. We consider it critical the decline of the functional impact in daily activities with conventional treatment, no matter whether the symptoms are motor, non-motor or both. The patient's judgment about this decline is essential to establish the advanced stage. This judgment does not always match with the rating scales used by the neurologist. We also think that the presence of invalidating non-dopaminergic symptoms, such as dementia, on-freezing gait or orthostatic hypotension, should define a stage different from the advanced.

\section{Relevant issues in advanced PD. Treatments and symptomatic response}

$\mathrm{PD}$ is, in fact, a multiple system degenerative condition. Apart from the substantia negra pars compacta, there is neuronal loss in areas such as the olfactory system, autonomic nerves, peduncle pontine nuclei, locus coeruleus, and raphe nuclei nucleus basalis of Meynert, limbic system or the associative cortex 4 . This broad degeneration explains many PD symptoms different from tremor, ridigity, and bradykinesia, the classic triad. Any therapy currently available only acts on the pathways modulated by dopamine, either binding the dopaminergic receptor or modifying the subthalamic nucleus hyperactivity, as in the case of surgery.

Over the last years, much attention has been paid to PD's non-motor symptoms ${ }^{5,6}$. Nevertheless, from a practical point of view, it could be more useful to divide PD symptoms into dopaminergic and non-dopaminergic. The first group responds to dopaminergic drugs, while the second group does not. The Sydney study followed up a cohort of PD patients for 15 years. After this time, non-dopaminergic symptoms become much more disabling than dopaminergic ones for most patients?

It is very important to learn which symptoms respond to dopaminergic medication. In this way, the neurologist may design the best possible therapeutic strategy, and the patient knows what to expect from the treatment.

In table 1, we have divided the Parkinsonian symptoms into dopaminergic and non-dopaminergic. The most troublesome non-dopaminergic symptoms are on-freezing gait, autonomic disorders, particularly orthostatic hypotension, and cognitive decline, which progresses to dementia in $80 \%$ of the cases $^{7,8}$.

Invalidating non-dopaminergic symptoms occur in later stages of PD and dramatically constrain the patient's daily activities. Before reaching this step, our current therapeutic capacity, properly applied, may extend the patient's functionality for a long period, even when the oral dopaminergic medication starts to fail.

Nowadays, the available PD therapy can be divided into two groups, conventional ${ }^{2}$ and device-aided treatment $^{9}$. The first group includes oral drugs and the rotigotine patch. The second one is formed by deep brain stimulation (DBS), continuous apomorphine infusion (APO), and intrajejunal levodopa (DUO).

When only conventional treatment was available, the patient got into a very disabling situation once it failed. The term advanced PD was coined to describe this situation, meaning a terrible and progressive life quality loss until death.

With the advent of device-aided therapies, the picture has completely changed. Several studies ${ }^{10-12}$ have shown that either DBS or infusion treatments allow for reasonable control of PD symptoms for many years. 
Table 1. Dopaminergic and non-dopaminergic symptoms in Parkinson's disease

\begin{tabular}{|c|c|c|c|}
\hline \multicolumn{2}{|c|}{ Dopaminergic symptoms } & \multicolumn{2}{|c|}{ Non-dopaminergic symptoms } \\
\hline Motor & Non-motor & Motor & Non -motor \\
\hline Bradykinesia & Pain* & $\begin{array}{l}\text { On-state } \\
\text { freezing }\end{array}$ & Dementia \\
\hline \multirow[t]{2}{*}{ Rigidity } & Depression* & $\begin{array}{l}\text { On-state } \\
\text { balance } \\
\text { disturbance }\end{array}$ & Psychosis \\
\hline & Apathy* & & \\
\hline \multirow[t]{3}{*}{ Tremor } & Anxiety * & $\begin{array}{l}\text { On-state } \\
\text { dysphagia }\end{array}$ & $\begin{array}{l}\text { Autonomic } \\
\text { disfunction }\end{array}$ \\
\hline & $\begin{array}{l}\text { Urinary } \\
\text { urgency* }\end{array}$ & & \\
\hline & $\begin{array}{l}\text { Lack of } \\
\text { concentration }\end{array}$ & & \\
\hline
\end{tabular}

*These symptoms may also have a non-dopaminergic origin and, therefore, fail to respond to dopaminergic drugs.

Since these device-aided therapies have been available, a reliable way to identify the advanced PD stage's onset has become crucial. The neurologist must be aware when the disease control starts to decline with conventional therapy and change to device-aided therapies. Hence, a definition for advanced PD should not be academic but operational, as it should give rise to a shift of therapeutic paradigm.

Another important issue is whether to call advanced stage to the whole period when conventional therapy is not sufficient for a good PD control. The patient's management is quite different when dopaminergic symptoms are dominant or when invalidating non-dopaminergic symptoms play the clinical picture's central role.

Due to the negative connotations the term advanced evokes, some authors have proposed different names, for instance, complex stage ${ }^{3}$.

\section{The search for criteria of advanced PD}

The availability of device-aided therapies has prompted the search for operative criteria to define advanced PD. Some pitfalls complicate this search, such as the absence of biomarkers, the disease heterogeneity, the patient's personal experience with the disease, the patient's employment status or the presence of non-dopaminergic symptoms, sometimes overlooked.
The NAVIGATE-PD study ${ }^{13}$ interviewed 103 experts from 13 countries about operative criteria to consider device-aided therapies, DBS, APO, and DUO. They concluded that loss in quality of life was the critical point. They proposed that (1) taking levodopa 5 or more times per day, (2) daily troublesome off-time over 1 or $2 \mathrm{~h}$, or (3) severe dyskinesia, with no specific duration, were red flags for possible advanced PD.

A group of Spanish neurologists carried on the CEPA (Consensus about the definition of advanced $P D$ ), also called CDEPA (Questionnaire for advanced $P D$ ), study ${ }^{14,15}$. They administered a questionnaire to other 240 Spanish neurologists, with a preferential dedication to $\mathrm{PD}$, about possible advanced stage criteria, applying the Delphi method. The panellists considered as definitive symptoms (1) the need for aid in the daily activities, (2) severe motor fluctuations, (3) severe dysphagia, (4) falls, and (5) dementia. The critical factor to the advanced stage was the disease duration.

Another study, with the Delphi method, involved experts from ten European countries ${ }^{16}$. The goals were to define clinical indicators for advanced PD, criteria for device-aided therapies, and the patients more suitable for each one of them. The panellists regarded the following clinical characteristics as suggestive of advanced PD. They are divided into three categories and ranked by order of importance.

1. Motor symptoms: moderate level of troublesome motor fluctuations, at least $2 \mathrm{~h}$ of the waking day with off-symptoms, at least $1 \mathrm{~h}$ of the day with troublesome dyskinesia, moderate level of dyskinesia, troublesome dysphagia, and daily oral levodopa at least 5 times a day

2. Non-motor symptoms: mild level of dementia, non-transitory troublesome hallucinations, moderate level of psychosis, non-motor fluctuations, and moderate level of nighttime sleep disturbances

3. Functional impact: repeated falls despite optimal treatment, need for help with the activities of daily life at least some of the time, inability to perform complex tasks at least some of the time, and moderate impaired mobility.

In the case of patients with advanced PD candidates for device-aided therapies, the clinical characteristics were reduced to:

1. Motor symptoms: troublesome dyskinesia and off-periods, at least $2 \mathrm{~h}$ of off-time, off-period postural instability, dystonia with pain, and freezing of gait during off

2. Non-motor symptoms: nighttime sleep disturbances, with no other specification 
3. Functional impact: limited activities of daily life.

The OBSERVE-PD study ${ }^{17}$ tried to correlate these clinical indicators with the neurologist's global assessment for advanced PD. It included 2615 patients from 18 countries. The correlation obtained was moderate ( $K=0.430 ; 95 \%$ IC $0.406-0.473$ ). According to their neurologists, within the patients diagnosed with advanced PD, $66 \%$ met the criteria for device-aided therapies. The authors highlighted that not all the patients treated with these therapies had advanced PD. As no more information was available, the authors speculate about the possible indications, such as poor levodopa tolerability, refractory non-motor symptoms, uncontrollable tremor, or functional needs in younger patients. Curiously, they did not consider these three latter situations as advanced PD.

The recent MANAGE-PD study has attempted to rank the criteria to identify advanced $P D^{18}$. The authors split the patients into three categories. Category 1 encompasses patients adequately controlled on conventional therapy. In Category 2, conventional therapy must be optimized to improve PD control. Finally, in Category 3, the disease control with this medication is not adequate, despite the optimization. To screen the patients, they applied two filters. The first one consists of checking whether the patients have at least one of these criteria: (1) 5 or more daily levodopa doses, (2) daily off-time of at least $2 \mathrm{~h}$, (3) unpredictable motor fluctuations, (4) troublesome dyskinesia, and (5) limitation in at least one activity of daily life. Meeting one or more of these problems should lead to a second filter to determine whether the patients need optimization or device-aided therapy. To validate these criteria, the authors presented ten clinical pictures with the three categories to 20 neurologists.

\section{The importance of the patient's judgment for the early identification of the advanced stage}

The aim for the early identification of advanced PD and the consequent shift in the therapeutic paradigm is to maintain the best possible patient's functionality. To achieve this, the neurologist must apply the appropriate therapy for each stage. The critical point is the change from intermediate to advanced PD since this should mean different disease management.

The recent study Euroinf 2 presents the characteristics of a cohort of 173 patients treated with device-aided therapies. It results quite striking that many patients start with some of these therapies in very advanced stages or even with remarkable axial symptoms ${ }^{19}$. Sometimes patients are on conventional therapy when they should have been on a device-aided therapy long before. For this reason, it is essential to identify when conventional therapy optimization is no longer the best option.

Most authors agree that the advanced stage commences when conventional treatment optimization does not provide adequate control for the disease $^{2,14,15,18}$. The term adequate control may be too vague as it depends on the neurologist's judgment and, mainly, on the patient's perception, demands, and expectations. Although there are some general recommendations, both conventional and device-aided PD therapies should always be personalized. The division of PD into different stages is not an abstraction. It must be adapted to each patient's reality, being, therefore, an operational definition.

The need for personalizing each case is well underlined in the aforementioned OBSERVE-PD study ${ }^{17}$. The correlation between the patient's neurologist's judgment and the criteria from a group of experts is only moderate. In the validation of the CEPA study ${ }^{15}$, the authors remark that the neurologist clinical judgment is the gold standard to determine the PD stage.

A point regarded as key in some study is the PD duration ${ }^{14}$. However, this condition is not always related to the disease stage. In our personal experience, the average disease duration before the onset of device-aided treatments has been eight and a $1 / 2$ years. Out of them, $30 \%$ were on these therapies after 6 years of PD (personal data not published). At the opposite end, there are patients with PD for over 20 years with sufficient autonomy had no dementia ${ }^{20,21}$. Although after 5 years, half of the patients get motor fluctuations ${ }^{22}$, a minority remains in good condition with no need for drug adjustments or significant non-motor symptoms after over 10 years $^{23}$. Hence, we think that the PD duration is not a reliable indicator of the advanced stage.

As mentioned above, the MANAGE-PD study ${ }^{18}$ considers three red flags for possible advanced $P D$, daily off-state over $2 \mathrm{~h}$, troublesome dyskinesia and 5 or more daily levodopa doses. Many levodopa doses mean several adjustments, but patients may have a reasonable control on 5 daily levodopa dose. If these adjustments do not avoid troublesome dyskinesia, the patient has bad PD control and advanced PD. The issue of the off-state is not so straight. Although a daily 2-h off-state is a red flag in PD, we must consider as well how the patient experiences this problem and how 
it affects their functional situation. Patients with demanding jobs may feel significantly limiting an off-state of $1 \mathrm{~h}$ a day. In contrast, more aged patients with no job responsibilities may tolerate better off-periods even over 2 hours. Hence, the patient's judgment may be more valuable than a score on a rating scale when both do not match.

Besides, we have to take into account the off-period duration and intensity, and not only motor but also non-motor symptoms. Pain, anxiety, apathy, depression, or lack of concentration may be very disabling during the off-state with or without motor symptoms. At our site, we have seen patients with episodes of severe off-state pain lasting $<1 \mathrm{~h}$, only responsive to infusion treatments. We also think that we should include within the advanced stage cases with disabling tremor, even if the other Parkinsonian symptoms do appropriately respond to conventional medication. Finally, we must not forget the patients with faltering on-state, even without important fluctuations. As this is mainly due to gastroparesis, a treatment skipping the oral route is usually effective.

\section{A stage beyond the advanced stage}

Nowadays, the advanced PD stage encompasses the whole period from the onset of the conventional treatment failure to the disabling non-dopaminergic symptoms dominance. However, this is not a homogeneous period with similar management. Many patients with device-aided treatments carry on an independent life. This does not happen with disabling non-dopaminergic symptoms.

Some studies searching for advanced PD criteria give the same defining value for advanced PD to dopaminergic symptoms refractory to conventional treatment and disabling non-dopaminergic symptoms. Both the CEPA study ${ }^{14,15}$ and the 2018 consensus study ${ }^{16}$ include as advanced PD criteria dementia, falls or onstate dysphagia, non-responsive to dopaminergic medication, along with dopaminergic symptoms, such as off-time pain, depression, and dyskinesia, all of them responsive to device-aided therapies. The patient's functionality is different enough to consider these situations as two distinct stages of PD.

The presence of disabling non-dopaminergic symptoms is not a contraindication for device-aided therapies but diminish their efficiency dramatically. Only infusion treatments, with low doses and close follow-up, are to try.
Table 2. Keys for the advanced Parkinson's disease

Conventional therapy does not provide adequate Parkinson's disease control

The term adequate control encompasses both motor and non-motor symptoms

The term adequate control must be personalized. It is very important the patient's perception of the treatment's functional impact

The identification of this stage should involve a shift to device-aided therapy

The earlier we identify this stage, the earlier we will be able to improve the patient's quality of life

Device-aided therapy only alleviates dopaminergic symptoms, either motor or non-motor

The term advanced Parkinson's disease should be restricted to the situation in which dopaminergic symptoms do not respond to conventional drugs, and non-dopaminergic symptoms are not disabling

If non-dopaminergic symptoms are disabling, we should speak of post-advanced stage

We suggest keeping the name advanced stage for the situation in which dopaminergic symptoms dominate the clinical picture but do not respond sufficiently to conventional treatment. Conversely, we consider a new PD stage for the situation in which disabling non-dopaminergic symptoms are dominant. In this case, the patient's functional state is severely diminished, and the therapeutic options significantly reduced. We propose calling this phase post-advanced stage. Something in this respect has been previously suggested ${ }^{15}$. In this study, the authors divide the advanced stage into advanced and late. Their criteria are the response to conventional therapy, partial in the first case, absent in the second. They do not mention refractory non-dopaminergic symptoms.

Table 2 shows the keys to advanced PD.

\section{Conclusions}

The key to advanced PD's definition stems from the lack of disease adequate control on conventional therapy. The early identification of this phase allows switching to device-aided therapies, which alleviate dopaminergic symptoms, either motor or non-motor. To determine advanced $P D$, a key point is the worsening of the patient's functional state. We must consider the off-period duration and its intensity, faltering on without fluctuations or disabling non-motor symptoms. The patient's judgment about their situation is essential to assess this stage. Sometimes it does not match with the rating scales. 


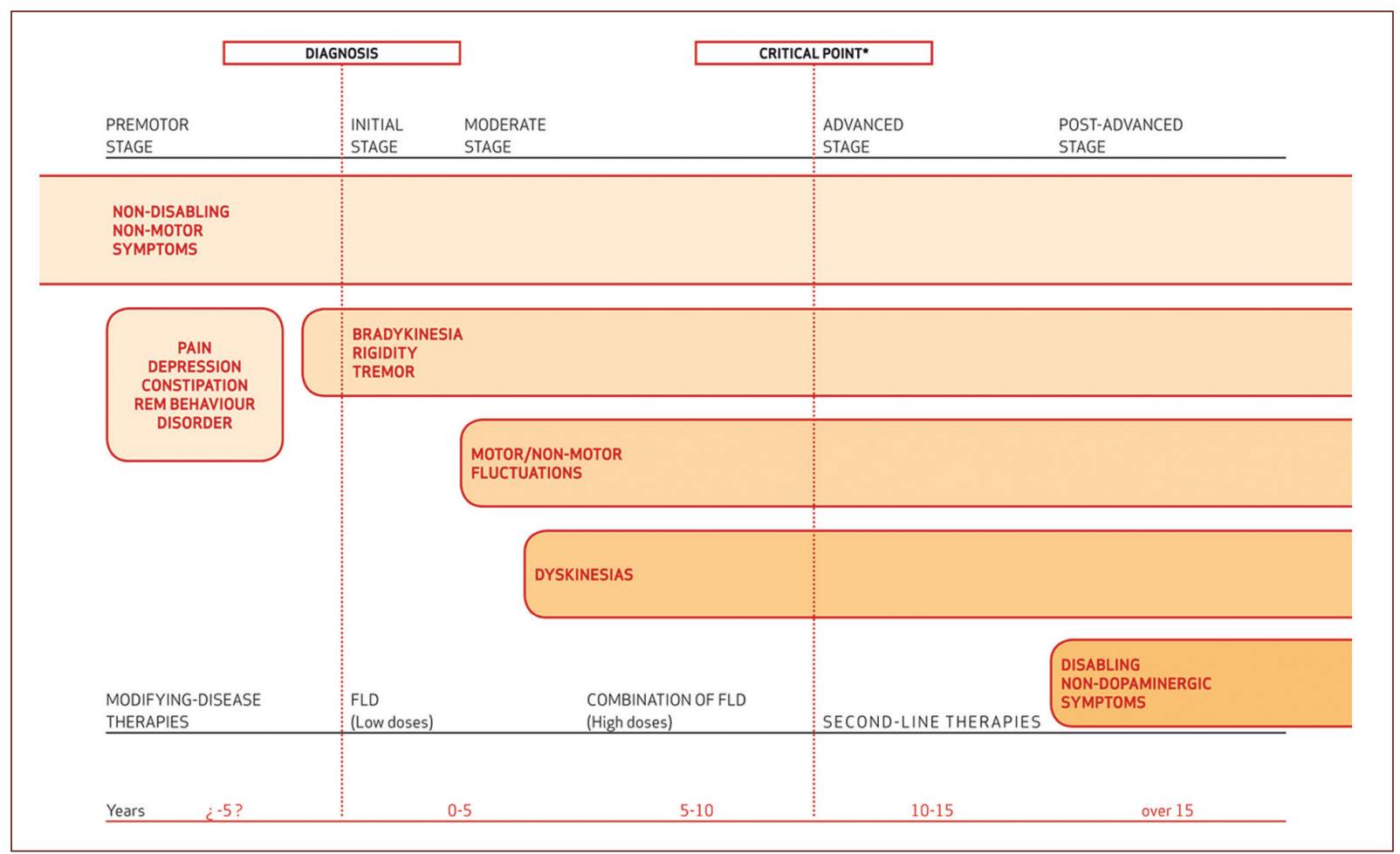

Figure 1. The natural history of PD. FLD first-line drugs (conventional therapy). *Critical point: the situation in which FLD became ineffective.

The patient's functionality in the advanced stage will depend on the presence of disabling non-dopaminergic symptoms. These symptoms usually appear in a later phase. We propose, therefore, differentiating two situations within what is called now advanced state. We should restrict this name advanced stage to the phase in which dopaminergic symptoms are dominant and respond to device-aided therapies. If disabling non-dopaminergic symptoms are present, we should speak of post-advanced stage.

Figure 1 shows a picture of the EP natural history, including the post-advanced stage.

\section{Acknowledgments}

The authors acknowledge the graphic designer and comic book artist Fausto Isorna his aid with the graphic material

\section{Funding}

The present work has not received any financial aid from the public sector, commercial entities, or non-profit organizations.

\section{Conflicts of Interest}

None.

\section{Ethical disclosures}

Protection of human and animal subjects. The authors declare that no experiments were performed on humans or animals for this study.

Confidentiality of data. The authors declare that no patient data appear in this article.

Right to privacy and informed consent. The authors declare that no patient data appear in this article.

\section{References}

1. Poewe W, Seppi K, Tanner CM, Halliday GM, Brundin P, Volkmann J, et al. Parkinson disease. Nat Rev Dis Primers. 2017:3:17013.

2. Kulisevsky J, Luquin MR, Arbelo JM, Burguera JA, Carrillo F, Castro A, et al. Advanced Parkinson's disease: clinical characteristics and treatment (Part I). Neurología. 2013;28:503-21.

3. Titova N, Martinez-Martin P, Katunina E, Chaudhuri KR. Advanced Parkinson's or "complex phase" Parkinson's disease? Re-evaluation is needed. J Neural Transm (Vienna). 2017:124:1529-37.

4. Dickson DW. Neuropathology of Parkinson disease. Parkinsonism Relat Disord. 2018;46 Suppl 1:S30-3.

5. Chaudhuri KR, Healy DG, Schapira AH, National Institute for Clinical Excellence. Non-motor symptoms of Parkinson's disease: diagnosis and management. Lancet Neurol. 2006:5:235-45. 
6. Schapira $\mathrm{AH}$, Chaudhuri KR, Jenner P. Non-motor features of Parkinson disease. Nat Rev Neurosci. 2017;18:435-50.

7. Hely MA, Morris JG, Reid WG, Trafficante R. Sydney multicenter study of Parkinson's disease: non-L-dopa-responsive problems dominate at 15 years. Mov Disord. 2005;20:190-9.

8. Sethi K. Levodopa unresponsive symptoms in Parkinson disease. Mov Disord. 2008;23 Suppl 3:S521-33.

9. Timpka J, Nitu B, Datieva V, Odin P, Antonini A. Device-aided treatment strategies in advanced Parkinson's disease. Int Rev Neurobiol. 2017;132:453-74.

10. Sesar Á, Fernández-Pajarín G, Ares B, Rivas MT, Castro A. Continuous subcutaneous apomorphine infusion in advanced Parkinson's disease: 10-year experience with 230 patients. J Neurol. 2017;264:946-54

11. Limousin P, Foltynie T. Long-term outcomes of deep brain stimulation in Parkinson disease. Nat Rev Neurol. 2019;15:234-42.

12. Antonini A, Poewe W, Chaudhuri KR, Jech R, Pickut B, Pirtosek Z, et al. Levodopa-carbidopa intestinal gel in advanced Parkinson's: final results of the GLORIA registry. Parkinsonism Relat Disord. 2017;45:13-20.

13. Odin P, Chaudhuri KR, Slevin JT, Volkmann J, Dietris E, Martínez-Martín P, et al. Collective physician perspectives on non-oral medication approaches for the management of clinically relevant unresolved issues in Parkinson's disease: consensus from an international survey and discussion program. Parkinsonism Relat Disord. 2015;21:1133-44.

14. Luquin MR, Kulisevsky J, Martinez-Martin P, Mir P, Tolosa ES. Consensus on the definition of advanced Parkinson's disease: a neurologists-based Delphi study (CEPA study). Parkinsons Dis. 2017;2017:4047392.

15. Martinez-Martin P, Kulisevsky J, Mir P, Tolosa E, García-Delgado P Luquin MR. Validation of a simple screening tool for early diagnosis of advanced Parkinson's disease in daily practice: the CDEPA questionnaire. NPJ Parkinsons Dis. 2018;4:20.
16. Antonini A, Stoessl AJ, Kleinman LS, Skalicky AM, Marshall TS, Sail KR et al. Developing consensus among movement disorder specialists on clinical indicators for identification and management of advanced Parkinson's disease: a multi-country Delphi-panel approach. Curr Med Res Opin. 2018;34:2063-73.

17. Fasano A, Fung VS, Lopiano L, Elibol B, Smolentseva IG, Seppi K, et al. Characterizing advanced Parkinson's disease: OBSERVE-PD observational study results of 2615 patients. BMC Neurol. 2019;19:50.

18. Antonini A, Odin P, Jalundhwala YJ, Schmidt P, Skalicky AM, Kleinman L, et al. MANAGE-PD: a clinician-reported tool to identify patients with Parkinson's disease inadequately controlled on oral medications-results from a vignette-based validation. Neurology. 2019;92 Suppl 15:P5.8-039.

19. Dafsari HS, Martinez-Martin P, Rizos A, Trost M, Dos Santos Ghilardi MG, Reddy P, et al. Eurolnf 2: subthalamic stimulation, apomorphine, and levodopa infusion in Parkinson's disease. Mov Disord. 2019;34:353-65.

20. Cilia R, Cereda E, Klersy C, Canesi M, Zecchinelli AL, Mariani CB, et al. Parkinson's disease beyond 20 years. J Neurol Neurosurg Psychiatry. 2015;86:849-55.

21. Hassan A, Wu SS, Schmidt P, Simuni T, Giladi N, Miyasaki JM, et al. The profile of long-term Parkinson's disease survivors with 20 years of disease duration and beyond. J Parkinsons Dis. 2015;5:313-9.

22. Poewe W. The natural history of Parkinson's disease. J Neurol. 2006;253 Suppl 7:VII2-6.

23. Hely MA, Morris JG, Traficante R, Reid WG, O'Sullivan DJ, Williamson PM. The Sydney multicentre study of Parkinson's disease: progression and mortality at 10 years. J Neurol Neurosurg Psychiatry. 1999;67:300-7. 